6 Johnson DR, Lubin H, Rosenheck R, Fontana A, Southwick S, Charney D. The impact of the homecoming reception on the development of posttraumatic stress disorder. The West Haven Homecoming Stress Scale (WHHSS). J Trauma Stress 1997; 10: 259-77.

7 Mulligan $\mathrm{K}$, Jones N, Davies M, McAllister P, Fear NT, Wessely S, et al Effects of home on the mental health of British forces serving in Iraq and Afghanistan. Br J Psychiatry 2012; 201: 193-8.

8 Department of Veterans Affairs, Department of Defense. VA/DoD Clinical Practice Guideline for Management of Post-Traumatic Stress. US Department of Veterans Affairs, 2010

9 National Institute for Clinical Excellence. Post-Traumatic Stress Disorder (PTSD): The Management of PTSD in Adults and Children in Primary and Secondary Care (Clinical Guideline 26). NICE, 2005.
10 Foa EB. Effective Treatments for PTSD: Practice Guidelines from the International Society for Traumatic Stress Studies. Guilford, 2009.

11 Wind TR, Komproe IH. The mechanisms that associate community social capital with post-disaster mental health: a multilevel model. Soc Sci Med 2012; 75: 1715-20.

12 Galovski T, Lyons JA. Psychological sequelae of combat violence: a review of the impact of PTSD on the veteran's family and possible interventions. Aggress Violent Behav 2004; 9: 477-501.

13 Karki R, Kohrt BA, Jordans MJD. Child led indicators: pilot testing a child participation tool for psychosocial support programmes for former child soldiers in Nepal. Intervention (Amstelveen) 2009; 7: 92-109.

\title{
Maria I of Portugal: another royal psychiatric patient of Francis Willis
}

\author{
Timothy Peters and Clive Willis
}

After 'curing' George III of acute mania in 1788-1799, Francis Willis's (1718-1807) psychiatric practice was considerably enhanced and he was persuaded to go to Portugal to cure the reigning Queen Maria I (1734-1816) of her mental illness. Surprisingly little has been published of the cause, nature and outcome of her chronic mental illness, which similarly affected two of her three sisters.

The antecedents of the Portuguese monarchy were from the Hapsburg, Bourbon and Braganza dynasties. All had a high prevalence of consanguineous marriages, especially the Hapsburgs in the form of uncle-niece, aunt-nephew and cousin marriages and this probably contributed to the prevalence of mental and other illnesses in their families.

Maria became queen on the death of her father from a stroke in 1776 and reversed many of the changes wrought by Pombal. Apart from an isolated episode of delirium in 1781, her first symptoms of mental ill health occurred in 1788 following the deaths from smallpox of her elder son and of her daughter and husband and their infant son; Maria felt considerable guilt as she had opposed smallpox inoculation on religious grounds. She was also tormented by fear for her father's soul for his role in the executions ordered by Pombal.

Unfortunately, unlike for George III, there is only a single extant medical report on Maria's illnesses but the regular dispatches by the British Envoy Robert Walpole have provided much detailed information. Intermittent depression, manic episodes and anxiety led to her son acting as Regent from 1792, officially confirmed in 1799.

Maria and her sisters Mariana and Dorothea all met the criteria for major depressive disorder. The arrival of Francis Willis in March 1792 was greeted with optimism. He advised a policy of moral management (psychotherapy) and adequate nutrition rather than medication, and initial reports were encouraging. However, unlike his treatment of George III, his role was advisory rather than having full control of Maria's care. This proved unsatisfactory: his attempts to remove Maria from the pressures of court life, including a sea voyage, were unsuccessful as all her couriers and governmental officials insisted on accompanying her. He declared her incurable, advised continuing care by physicians from the University of Coimbra and departed for England in August some f16000 wealthier.

Maria and her affected sister continued to be chronically mentally ill; Dorothea died aged 32 in 1771, but Maria and Mariana endured the transfer of the Portuguese court to Brazil in 1807, the result of the Napoleonic advance on Lisbon. They died in Rio de Janeiro aged 82 and 77 , respectively.

Maria's regent and successor John VI suffered from bouts of melancholia and had a highly dysfunctional marriage. His two sons, Pedro and Miguel, returned to Lisbon and engaged in a major civil war against one another in the 1830s, which arguably fanned the flames of republicanism, with subsequent abolition of the monarchy in both Brazil (1889) and Portugal (1910). 